\section{THE BACTLLUS ABORTUS AND HUMAN ABORTION.}

To the Editor of THE LANCET.

SIR,-The last edition of M. J. Rosenau's " Preventive Medicine and Hygiene" (p. 777) contains the following: ". . . Bacillus abortus which may contaminate milk, .... but there is no evidence that it is harmful to man." I have known several outbreaks in this county, but $I$ have never been able to trace any connexion with abortion in the human.

I am, Sir, yours faithfully, SIDNEY BarWISE.

New County Offices, St. Mary's Gate, Derby, Nov, 6th, 1922 .

\section{THE PHYSICIANS' CODE.}

\section{To the Editor of THE LANCET.}

SIR,-Following your annotation under this heading in THE LAANCET of Nov. 4th, dealing with changes just made in the by-laws of the Royal College of Physicians of London, relating to membership of the College, may I be allowed to point out how these changes affect the present Members? The diploma of Member, which has ever since its institution given the status of physician, is now made a general practitioners' diploma, the conditions which restricted its holding to a pure physician being removed. It is apparently intended by the College to limit physicians to the body of elected Fellows. Members who have not been elected Fellows, but who have practised as pure physicians for many years, and who hold, some of them jealously, to the high ideal which the College embodies, now find themselves virtually deprived of their physicians' diploma, by a change made without their cognisance or consent.

I shall be glad to be corrected if I have misapprehended the facts. - I am, Sir, yours faithfully,

Devonshire-place, W., Nov, 6th, 1922 . R. Hingston Fox.

\section{"FORAGE" OF PROSTATE. \\ To the Editor of THE LANCET.}

Sir,-No doubt English surgeons are well acquainted with the ancient practice of tunnelling the prostate and are also familiar with the modern "forage." I doubt, however, if the latter procedure is fully appreciated in this country, nor is it advocated as an alternative to prostatectomy-for the relief of retention, in cases of hypertrophied prostate.

Possibly a brief description of my own case may be of interest. I am now in my sixty-eighth year, and have invariably enjoyed good general health. Some twelve years ago I first noticed frequency of micturition, which continued a few years, with occasional onsets of urgency. This condition was followed in time by hesitancy, diminution in the volume of the stream, and inability to project it forwards. These symptoms progressed up to recently, and, knowing that my ailment was hypertrophy, which was almost certain to increase, I consulted a specialist in urology. He advised that I should pass a bougie myself twice a week and observe results. However, not liking the idea of beginning a catheter life, and being sceptic as to the after-results of the only alternative, enucleation, I placed myself under the treatment of Dr. Georges Luys of Paxis. After the usual superficial examination, he dilated my urethra up to No. 60 Bénigué, and then passed a special urethroscope, by which he obtained a complete view of the prostatic urethra, and was also enabled to see and control the manipulations of the electrode by which he subsequently reduced the obstructing prostate. He found two large mucous polypi, which he destroyed with the electro-coagulation cautery, and observed a slight hypertrophy of the middle lobe of the prostate. After a lapse of eight days, the original symptoms persisting, I then submitted to "forage." 'This operation consisted of four applications of the cautery to the middle lobe, the duration of each being about ten seconds. The resulting pain was not intolerable. $\Lambda$ portion only of the offending lobe was subjected to the action of the cautery, and the denuded surface allowed to cicatrise. Twelve days later the final "forage" was undertaken, which completely eradicated all hindrance to a free flow of urine. In fact, before leaving the operation couch my bladder was filled with warm boric solution, and I was astonished to see myself enabled to urinate freely and forcibly, for the first time after many years of anxiety. It is noteworthy that $I$ was not confined to my room in the clinique, or retained in bed, except on the days of actual operation. The remainder of my time in Paris I spent in sightseeing and in mild walking exercises.

Two months have now passed since the last operation of forage, and $\mathrm{I}$ am perfectly well in every respect. I still micturate more frequently than normal, but there are no unpleasant sequelæ. Hardly one-third of my prostate has been removed, and the seminal appendages are uninjured. A full description of Dr. Luys's technique and a discussion of the indications for this treatment will be found in Paris Chirurgical, January, 1918. I understand that since the publication of this article Dr. Luys has operated on over a hundred cases of hypertrophy of the prostate with satisfactory results.-I am, Sir, vours faithfully,

ARTHUR FInegan, L.R.C.P. Irel.

Authors' Club, Whitehall Court, London, S.W. Oct. 27 th, 1922 .

\section{THE USE OF GOLD CAPS.}

To the Editor of THE LANCET.

SIR, - A note of warning is overdue with regard to the indiscriminate condemnation of gold caps on molar teeth by so many medical men. It amounts almost to an obsession with some. That many gold caps are responsible for an insanitary mouth owing to faulty construction and application, is incontrovertible. That the well-made cap, well applied to a well-prepared though broken-down tooth incapable of further supporting a filling, is an effective and desirable substitute for extraction, is also incontrovertible. The gold cap was one of the most brilliant conceptions in dentistry for the preservation and utilisation of extremely defective molar crowns with good roots. If it has been taken advantage of by faulty workmanship, that is no reason for its general condemnation. In the search for a cause of some obscure dyspeptic, rheumatic, or arthritic trouble " those gold caps must be removed" is becoming quite a medical shibboleth, to the detriment and discomfort of many a patient who has found the sacrifice of useful well-capped teeth unattended by the relief to their constitutional trouble sought for. The substitution of a denture does not improve the patient's chagrin at their loss.

Ill-fitting, septic, and defective gold caps should invariably be scrapped, but the line should be drawn and the medical man is well advised who leaves the decision to the dental surgeon.

I am, Sir, yours faithfully, Pracy Edgelow.

Devonshire-place, W., Nov. 6th, 1922 .

Alvarenga Prize. - The next award of the Alvarenga prize of the College of Physicians of Philadelphia, amounting to about $\$ 300$, will be made on July 14th, 1923 , provided that an essay deemed by the committee of award to be worthy of the prize shall have been offered. Fissays intended for competition may be upon any subject in medicine cannot have been published, must be typewritten, and if written in a language other than English should be accompanied by an English translation, and must be received by Mr. John H. Girvin, the Secretary of the College, 19, South 22nd Street, Philadelphia, Pa., U.S.A., on or before May lst, 1923. Each essay must be sent without signature, but must be plainly marked with a motto and be accompanied by a sealed envelope having on its outside the motto of the paper and within the name and address of the author. It is a condition of competition that the successful essay or a copy of it shall remain in possession of the College ; other essays will be returned upon application within three months after the award. 